\title{
Salve os inglórios! \\ Historicidade e memória em \\ $O$ mestre-sala dos mares
}

Thiago Kater

\section{Resumo}

A canção $O$ mestre-sala dos mares, composta por João Bosco e Aldir Blanc e lançada no álbum Caça a Raposa em I975, é um dos tantos exemplos em que foi possível conciliar a crítica à ditadura e o sucesso mercadológico na indústria fonográfica. A canção se estrutura como um discurso histórico elogioso a respeito da Revolta da Chibata. Este ensaio pretende propor uma análise da letra desta canção, entendendo-a enquanto documento histórico ou discurso historiográfico e, portanto, passível de interpretações que permitirão desdobrar conceitos e vinculações teóricas.

Palavras-chave: Música Brasileira - Revolta da Chibata - Memória. 


\section{Introdução}

Este ensaio propõe uma análise da letra da canção $O$ mestre-sala dos mares, composta por João Bosco e Aldir Blanc em I975 e lançada no álbum Caça a Raposa com o selo RCA.

A proposta decorre de sua apreciação como documento histórico e, como tal, permite uma análise através dos significados abarcados em seu tratamento artístico e estético. Entendendo-a enquanto um discurso, essas escolhas farão parte de uma visão de mundo, de uma ideologia, na sua relação intrínseca com a sociedade a qual pertence. Ao cabo, ela própria pode tornar-se alvo de um novo discurso.

Tendo isso em mente, pretende-se analisar a letra da canção evidenciando as reverberações suscitadas e suas conexões com diversas problemáticas tanto do período histórico de sua composição - suas referências e balizas temporais - quanto aqueles elementos que escapam do domínio autoral: a intenção é refletir sobre prováveis sentidos polissêmicos para a obra.

Metodologicamente, Luiz Tatit (I989-90) propõe uma análise centrada na articulação da melodia com a letra da canção. Todavia, adverte-se que, também pelo recorte proposto, o método não será utilizado pela assumida incompetência deste autor em fazê-lo. Abdica-se, assim, de apontar saídas não embasadas técnica e teoricamente. Ressalta-se que o uso de canção ou música servirá como referência à letra da música - o que será efetivamente analisado.

Outra ressalva é que a análise da canção não se dará no contexto do álbum - apesar de haver tal amarração. Tais escolhas metodológicas podem, aparentemente, prejudicar uma apreensão geral, no entanto, para a reflexão que se sugere, esta letra pode ser vista como um documento-monumento (LE GOFF, 2006), um discurso repleto de camadas de representação e sentido, acumuladas pelo e do conflito entre as histórias e memórias em jogo.

\section{A canção através de suas interpretações}

A obra em questão demanda certas explicações. A intenção dos compositores parece bem clara: discurso fechado e coerente entre a história contada/cantada e o momento histórico da época, um referenciar-se no presente retomando o passado.

Já existe alguma discussão a respeito dela, de seu intuito e de seu contexto. A parca importância dada à Revolta da Chibata na memória nacional trans formou $O$ mestre-sala dos mares em um dos principais mecanismos mnemônicos do movimento de João Cândido. O direito à memória da Revolta, recuperada pela ação do movimento negro e de outros atores sociais empenhados em sua valorização, não retirou da canção esse efeito. 
Sua utilização em diferentes trabalhos acompanha propostas de leituras diferentes, mas não necessariamente contrastantes. Podem-se perceber grosso modo algumas direções dessas análises.

No início dos anos 2000, a dissertação de mestrado de Alexandre Fiuza (200I) propõe um estudo da obra de João Bosco e Aldir Blanc durante a ditatura militar. Nela, entre diversas outras propostas, encontra-se a analogia entre a opressão dispensada à Revolta da Chibata, a narrada em $O$ mestre-sala dos mares e a que acontecia no governo militar. Fiuza ainda pensa essa música como importante instrumento de ensino de história, propondo a análise dessas três dimensões em sala de aula.

Reflexo da retomada da Revolta da Chibata enquanto marco histórico fundamental para as caracterizações e representações do Brasil, assim como na luta por direitos humanos, o Projeto Memória 2008, organizado pela Acan, Petrobrás e Fundação Banco do Brasil, lançou João Cândido. A luta por direitos humanos. O livro de memórias fotobiográfico, que inclui parte de entrevistas de João Gândido, inicia seu primeiro capítulo partindo da canção e explica o reaproveitamento que Aldir Blanc e João Bosco fazem do livro de Edmar Morel, lançado em 1958 - A Revolta da Chibata -, o primeiro a associar Cândido ao Dragão do Mar, Francisco José do Nascimento. Por ora isso não será discutido, pois será posteriormente detalhado.

Maria Marçal (2009) também se vale da canção como referência para seu artigo, denominando João Cândido pelo epíteto cunhado por Aldir Blanc e João Bosco. Em O mestre-sala dos mares: a Revolta da Chibata e a consciência histórica dos alunos, Marçal deixa transparecer a influência mnemônica que a canção lhe traz e, como Fiuza (200I), a transforma em mecanismo para aprendizagem.

Em um artigo centrado especificamente na análise da canção, Edwilson da Silva Andrade a propõe

como eficaz instrumento de ação pedagógica para, através do prazer estético da letra, analisarmos a sociedade, seus posicionamentos ideológicos e as situações históricas que se constroem em seu interior, tentando apontar os objetos simbólicos e suas significações, bem como o papel das políticas de silenciamento (ANDRADE, 2009, p. I).

Andrade apresenta uma análise perspicaz.

Apesar de não se centrar especificamente em $O$ mestre-sala dos mares, e só citá-la esporadicamente, outra tese dialoga pertinentemente com a temática em questão. O lugar dos galos de briga: Aldir Blanc e a década de 1970, de Cícero Batista (20IO), apresenta um balanço da obra do compositor, em especial do álbum 
Galos de briga em meio à ditadura, a parceria com João Bosco e a inserção deles no debate sobre o papel social do artista.

A dissertação de Cláudio Sousa (2012) Marinheiros em luta: a Revolta da Chibata e suas representações é um estudo sobre a memória e a construção de sentido a respeito da sublevação de João Cândido contra os castigos físicos, a carga de trabalho e o péssimo tratamento dispensado pela Marinha aos marujos de baixa patente. O diferencial é sua intenção de apreender o significado histórico da Revolta através das diversas leituras e arranjos realizados a partir dela, refletindo as disputas de memórias em jogo, as tentativas de negação e valorização. E Sousa não poderia se furtar de discutir o papel de $O$ mestre-sala dos mares no imaginário que se constrói da Revolta a partir da canção e a forma- representação que dela se retira. Seus apontamentos serão alinhavados ao texto em momento oportuno.

Outro texto que tem $O$ mestre-sala dos mares como eixo central de sua construção é A Revolta da Chibata entre cascatas, estátuas e navios de Oliveira \& Siqueira (20I3). Tendo a canção como fio narrativo, os autores fazem um retrospecto do que foi a Revolta da Chibata em seus aspectos legais e simbólicos.

Apesar do intuito do ensaio não ser a Revolta da Chibata, mas o poder que a canção $O$ mestre-sala dos mares possui para elencar problemáticas sobre memória e historicidade, vale a pena ressaltar a existência de uma historiografia que se debruça de maneira mais intensa sobre a Revolta em si. Se seu centenário reavivou o interesse de pesquisadores como forma de reafirmação de sua memória, valem exemplos de trabalhos e balanços produzidos, recuperando primeiramente Morel (I986) com o clássico A Revolta da Chibata; ou A Revolta da Chibata fazcem anos de Mário Maestri (2OIO); e finalmente Sílvia Almeida (2OII) com Do marinheiro João Cândido ao almirante Negro: conflitos memoriais na construção do herói de uma revolta centenária.

\section{A canção na sua conjuntura}

Em meados dos anos I960, um processo que culminaria com o golpe de Estado e a instalação de uma ditadura militar no Brasil alteraria a dinâmica da sociedade brasileira por mais tempo do que o previsto - suas consequências ainda perambulam por aí. A censura e a violência contra os opositores eram mecanismos frequentemente empregados a fim de promover uma coerção social mantenedora do regime.

No contexto da ditadura militar e no pós-AI-5, as chamadas canções de protestos, que provocavam o governo militar ao apresentar os desmandos 
políticos e mazelas sociais através de uma postura crítica, viam-se como estandarte de uma conscientização e de uma mudança no país.

Essas canções tonaram-se sucesso em um público diverso social e politicamente, e foram requisitadas pela indústria fonográfica por conta de sua rentabilidade mercadológica. As músicas que iam contra a sociedade de consumo e o governo que a fortificou no Brasil eram, no entanto, um dos carros-chefes dessa indústria (NAPOLITANO, 2010, p. 389).

Eram representados principalmente por jovens (vários oriundos das classes médias urbanas) e universitários que, apesar de desejarem ser vistos de certo modo como continuadores da Bossa Nova e da MPB, assumiram uma nova postura (BATISTA, 20I0, p. 60). É importante ressaltar que, no início da década de I970, havia uma sensação, ou melhor, uma ameaça de "vazio cultural" no Brasil (VENTURA, 2000, p. 45-60).

Sem dúvida a censura e a ação do AI- 5 influenciaram a produção artística nacional, mas não a intimidaram a ponto de anulá-la. Não era mais possível atuar como se havia feito, era preciso novos modos para orquestrar uma "conscientização política". Zuenir Ventura nos aponta essa transformação:

As tendências instrumentalizadoras da atividade artística, que transformavam a obra num simples meio condutor de recados políticos, deram lugar a uma compreensão mais profunda dos limites e da autonomia da criação artística. Enquanto no período anterior a pressa em influir logo e diretamente - dizia-se ganhar as pessoas - dava às músicas, por exemplo, um tom de agitação imediata e passageira, hoje o populismo foi substituído por uma seriedade de pesquisa expressiva e por um aprofundamento temático [...] (VENTURA, 2000, p. 65).

Evidencia-se então que:

Longe de ser um mero desdobramento passivo das lutas políticas do período ou dos movimentos musicais da década anterior, a MPB dos anos 1970 experimentou o auge da popularidade e maturidade criativa, elementos que, por sua vez, não traduzem diretamente nem uma penetração universal nas audiências populares, nem uma autonomia estética idealizada voltada para poucos. A canção engajada, em todas as suas variantes, não apenas dialogou com o contexto autoritário e as lutas da sociedade civil, mas ajudou, poética e musicalmente falando, a construir um sentido para a experiência social da resistência ao regime militar, transformando a "coragem civil" em tempos sombrios em síntese poético-musical (NAPOLITANO, 20I0, p. 390). 
Em $O$ mestre-sala dos mares, identificamos correlações com a "experiência social da resistência" (NAPOLITANO, 20Io, p. 390) e a postura crítica perante o momento em que João Bosco e Aldir Blanc compõem a música. A tática usada pela dupla para a contestação do presente é apresentar o passado e o contexto sociopolítico da população como fonte de reflexão.

É de certo modo aquilo que Napolitano propõe sobre os trabalhos desses compositores:

Aldir Blanc e João Bosco, donos de uma das obras mais contundentes (e consistentes) dos anos I970, fundiram crônica social e poesia para retratar o cotidiano das classes populares sob o autoritarismo, afirmando ora a dignidade, ora a capacidade de ironia crítica do cidadão comum (NAPOLITANO, 20IO, p. 392).

No lugar de crônica social do presente, a história em sua fusão com a poesia: a emblemática Revolta da Chibata ocorrida em I9Io no Rio de Janeiro (então capital federal). Em fins do citado ano, um grupo com mais ou menos mil marinheiros de baixa patente se rebela e toma os navios de guerra ancorados na baía de Guanabara e aponta os canhões e as armas do navio para a cidade. Os marinheiros eram quase predominantemente negros e mestiços, oriundos de regiões periféricas do Rio de Janeiro e do Brasil. Entre as demandas exigiam melhores condições e o fim de castigos corporais, principalmente o uso da chibata (ALMEIDA, 2OII).

Após cinco dias de revolta e forte repercussão por parte da sociedade e da imprensa, o governo atendeu aos pedidos dos marinheiros insatisfeitos. No entanto, pouco tempo depois, iniciou uma busca e desligou os indivíduos considerados perigosos e que poderiam se rebelar novamente, quebrando assim a promessa de anistia. Por conta disso, outra rebelião estoura, desta vez massacrada pelas Forças Armadas da República. Prisões, violência e fuzilamentos são aplicados aos revoltosos. Dos que permaneceram presos e alguns anos depois absolvidos, mas marginalizados, um receberia, posteriormente, especial atenção da historiografia, o marinheiro João Gândido, visto por muitos como um dos mentores e líder da revolta (ALMEIDA, 20II).

Um imaginário se criou sobre ele. Marcado pela violência do Estado perante as reivindicações contra maus tratos e abusos do poder, João Cândido tornou-se símbolo eleito e representante de uma série de movimentos sociais postos em situação semelhante. Construída a imagem histórica do herói não consensual para a história nacional, outra visão surge, a que marginaliza e oculta esse acontecimento histórico. Por esse discurso reforçar o do poder, a história tida como oficial partilha desse silêncio, escamoteando toda a problemática envolvida no evento. 
Baseando-se nessa história, João Bosco e Aldir Blanc escreveram essa letra. Há uma clara relação entre o momento histórico cantado e aquele em que os autores da música viviam. Paralelos eram inevitáveis. Tanto que a versão original foi censurada pela ditadura e uma modificação foi necessária para que ela pudesse ser comercializada/lançada. Um dos pontos mais incômodos para a censura era a violência explicitamente dirigida aos negros e a alusão à Marinha - para a Censura, suscitar movimentos rebeldes, desqualificar as instituições militares e associar a permanente violência às classes baixas era ofensivo (ANDRADE, 2009, p. 7 e 8). Enfim, há relatos dos autores sobre esse processo, mas aqui eles não serão utilizados.

Decorre, no entanto, que diversas interpretações de $O$ mestre-sala dos mares prendem-se a esse paradigma: uma crítica à ditadura e à história oficial e um elogio a movimentos rebeldes que lutam em prol da liberdade das classes menos abastadas ou contra as ingerências do Estado.

O que se busca aqui é ultrapassar esse tipo de análise, plenamente colada entre a realidade e a intencionalidade dos compositores, e propor novas possibilidades para sua compreensão, através de mecanismos e conceitualizações que, apesar de manterem a coerência interna da canção e não descartarem, de forma alguma, aquele tipo de interpretação, tentam penetrar em outros eixos de análise.

Será analisada somente a versão liberada pela censura. Há dois motivos para isso. A comparação entre a versão original e a censurada pode gerar pequenas diferenças interpretativas, no entanto, essa sensação só é criada, obviamente, ao compararem-se as duas versões, algo que o público não pôde fazer. Isso leva ao segundo e principal motivo. A censura era - infelizmente - um dado concreto com que os artistas precisavam dialogar. As escolhas e ajustes finais fazem parte de um repertório tão intencional quanto aquele da ideia original, erroneamente vista como pura. A versão censurada é uma releitura autoral deles próprios e por isso levada em conta per si, sem necessidade de comparação.

\section{A letra da canção}

Há muito tempo nas águas da Guanabara

O dragão do mar reapareceu

$\mathrm{Na}$ figura de um bravo feiticeiro

A quem a história não esqueceu

Conhecido como o navegante negro 
Tinha a dignidade de um mestre-sala

E ao acenar pelo mar na alegria das regatas

Foi saudado no porto pelas mocinhas francesas

Jovens polacas e por batalhões de mulatas

Rubras cascatas jorravam das costas

dos santos entre cantos e chibatas

Inundando o coração do pessoal do porão

Que a exemplo do feiticeiro gritava então

Glória aos piratas, às mulatas, às sereias

Glória à farofa, à cachaça, às baleias

Glória a todas as lutas inglórias

Que através da nossa história

Não esquecemos jamais

Salve o navegante negro

Que tem por monumento

As pedras pisadas do cais

Salve o navegante negro

Que tem por monumento

As pedras pisadas do cais

Mas faz muito tempo

\section{v. O mestre-sala dos mares: historicidade e memória em análise}

A promessa de uma história, de uma narrativa sobre tempos longínquos é uma das primeiras impressões causadas pelo verso inicial "Há muito tempo nas águas da Guanabara”. Enquanto suprime qualquer delimitação histórico- temporal - como o era uma vez dos contos de fadas - delega ao espaço geográfico o papel de ponto referencial.

Essa estratégia pode ser encarada de um ponto de vista funcional. Localizá-lo em um espaço conhecido pode servir como apelo afetivo ao interlocutor ao criar uma sensação de reconhecimento, pois se trata de uma localidade relativamente célebre para os brasileiros: as "águas da Guanabara”.

I A partir de I5 de março de I975, houve a fusão dos estados da Guanabara e do Rio de Janeiro, mantendo a denominação de estado do Rio de Janeiro. Decorrente desse episódio, que ocorre no mesmo ano em que a música foi composta, interroga-se, mas não se apresenta uma resposta definitiva, sobre 
Esse espaço se constitui enquanto materialidade onde se transcorrerá algo ainda a ser contado. Mas não só. Como tal localização geográfica é contemporânea, torna-se assimilável pelo cotidiano das pessoas, pelo imaginário e ainda permite um olhar histórico sobre esse espaço. É algo que sugere a arqueologia: "todo tipo de artefato, tudo que é resultado da ação do homem sobre a realidade física [...] inclusive, as paisagens, na medida em que elas são alteradas pela ação humana e apropriadas culturalmente [...] [têm] função de documento" (MENESES, I980, p. 3).

Documentos históricos e objetos da arqueologia, as paisagens atuam no processo de significação pessoal, sendo ao mesmo tempo alvo e gestoras de memórias. A forma com que uma sociedade interage em e com um local aponta, também, para aspectos significantes de sua organização. Um lugar possui um acúmulo de experiências, sua história na longa duração, sua própria historicidade.

Se o espaço geográfico está demarcado, João Bosco e Aldir Blanc não balizam temporalmente seu relato, apesar de que, durante a canção, revelam-se diversos indícios. No entanto, o que se propõe nesse ensaio é encarar a inexistência do recorte histórico - posto pelo "Há muito tempo" - o que pode gerar possibilidades interpretativas e teóricas importantes.

Inicialmente, o próprio contexto histórico em que foi composta a obra sugere interpretações, como observado no levantamento bibliográfico. A indeterminação do passado, colocando-o imerso num tempo não referenciado, destituiu-o, de certo modo, de responsabilidades e ligações com o que ocorre no presente. Através dessa perspectiva, o que for dito na canção não terá relação intrínseca com o contemporâneo, sendo assim, livre, a priori, de intencionalidades dúbias.

A ideia é de um tempo que se transformou e foi esquecido, que já não mais existe, purgando-se de toda responsabilidade com o presente. Com isso torna-se, teoricamente, possível falar sobre história sem apresentar um juízo de valor do presente. Portanto, parece ser esse um dos artifícios dos compositores, uma abstração temporal a fim de driblar as possíveis atuações da censura.

Não obstante, outro intuito deve ser ponderado ao articular uma indeterminação histórica-temporal e a especificação de um espaço geográfico:

a qual local a canção faz referência ao cantar "nas águas da Guanabara": a baía da Guanabara, local da Revolta da Chibata, ou ao Estado da Guanabara (atual cidade do Rio de Janeiro)? Aparentemente trata-se da baía. 
causar estranheza e curiosidade no público. O que teria acontecido há tanto tempo neste local que eu conheço e que me é palpável? Tal pergunta é que será respondida pelos compositores ao longo da canção. Como nas velhas narrativas, a vontade do saber é ponto importante dessa construção.

Após deixar em suspensão o tempo e evidenciar o lugar em que a narrativa vai se desenvolver, os compositores nos apresentam um sujeito ressurgido sob uma nova forma. Essa reaparição não deixa de ser problemática.

"O dragão do mar" é uma citação direta a Francisco José do Nascimento, um jangadeiro cearense que trabalhava na Capitania dos Portos e atuou de forma incisiva na luta contra a escravidão. Na segunda metade do século XIX, o tráfico negreiro interno era a principal fonte de escravos para o Centro-Sul, enquanto o Nordeste tornara-se o fornecedor. O jangadeiro, apelidado de Dragão do Mar, localizava as embarcações que pretendiam traficar escravos e, juntamente com seus companheiros, recusava-se a fazer o transporte dos cativos da costa para os navios negreiros, impedindo assim o comércio. O personagem torna-se notório e sua figura transforma-se em símbolo, principalmente no Geará, da luta contra a escravidão.

Visto que o "dragão do mar reapareceu na figura de um bravo feiticeiro", pode-se cogitar que o próprio Francisco José do Nascimento reencarnado em outro é que volta à tona (SOUSA, 20I2, p. 7I). No entanto, o próprio termo "na figura de" não leva a crer no fenômeno transcendental, mas, sim, que a equiparação se dará entre seus atos com os de um "bravo feiticeiro", reaparecido como o mesmo intuito do "dragão do mar".

O que fica latente é a perspectiva do reaparecer na história. Se a historicidade cronológica e linear é insuficiente para resolver as possibilidades de retorno, problematizá-la através de outras perspectivas do regime temporal é a saída. Pelo menos três hipóteses são cabíveis.

Uma surge com Marx - a inspiração vem de Hegel - e a citação encontra-se em seu livro 018 Brumário de Luís Bonaparte no qual afirma que a história repete-se sempre duas vezes, a primeira como tragédia, a segunda como farsa (MARX, I978, p. 329).

A segunda possibilidade é pensar em outros regimes de temporalidade, não envoltos em uma perspectiva linear da história. De Heráclito a Nietzsche, cada qual a sua maneira, partilharam a visão de uma história cíclica, na qual o retorno é a regra.

Por fim, pode-se compreender o presente e a história como um acúmulo da longa duração, valendo-se muito mais das continuidades do que das rupturas. Os lugares e o ser humano são completamente impregnados de história, de elementos que se arrastam a se perder de vista, são o contorno do devir. 
Uma perspectiva como a de Gramsci (I97I, p. 324) observa que: "a consciência daquilo que alguém realmente é [...] é 'conhecer a si mesmo' como produto do processo histórico que até o momento depositou nele uma infinidade de vestígios, sem deixar um inventário".

Mesmo que tenha sido "há muito tempo", há algo que ainda teima em ser como foi e alguém que vivencia esse tempo que se arrasta. Através dessa perspectiva, João Bosco e Aldir Blanc apresentam "o dragão do mar", um personagem que lutou contra a escravidão, a violência contra o ser humano - em especial, contra a população negra - e que ressurge através de outro personagem que, por sua vez, tem diante de si esse acúmulo histórico, resultado de continuidades e permanências ainda a se enfrentar.

Do significado adquirido com o uso de "feiticeiro", há realmente uma carga menos incômoda aos olhos da censura, até pela própria marginalização social imbuída nessa religiosidade, devido a sua ligação às religiões afro-americanas e indígenas (SOUSA, 20I2, p. 73). O notório, entretanto, é indica-lo como "a quem a história não esqueceu". Isso implica dizer que se ele não foi esquecido é porque existem elementos que necessariamente são obliterados. A seleção dos fatos, eventos e agentes é, de fato, uma necessidade posta ao historiador. A própria ideia de completude é intangível. Mas o debate há muito estabelecido diz respeito não à totalidade, mas, sim, a quem beneficiará o discurso do historiador.

Nesse caso, talvez, parte da memória sobre o evento fomentou-se pela própria canção. Outra possibilidade é que ela só corrobore o que já faz parte do imaginário popular, até porque o duo heroico é atrelado a essa parcela da população. Com a perspectiva de continuidade, marca indelével da historicidade presente na canção, a inserção de João Cândido na história, e seu consequente elogio, é acompanhada por uma valorização indireta de diversos outros movimentos semelhantes, sejam eles passados (aquele do "dragão do mar"), ou os que ocorrem na contemporaneidade que, no contexto da canção, era o combate à ditadura.

O fato do "navegante" ser negro é fator interpretativo determinante da obra. Mas, antes, vale refletir sobre seu caráter admirável, sua "dignidade de um mestre-sala". Uma das figuras centrais do carnaval, a elogiosa comparação advém do mestre-sala ser o responsável por acompanhar a porta-bandeira da escola de samba, devendo a todo instante cortejar tanto sua portadora, quanto o estandarte, símbolo maior e mais ostentado do grupo carnavalesco. A alegoria atua a fim de alterar sua posição de navegante para aquele que organiza e zela pelo mar e por aqueles que lá estão - juízo reforçado pelo título da canção. O domínio de sua função era tal que era capaz, mesmo assim, de "acenar [...] na alegria das regatas". 
Regatas foram eventos esportivos muito corriqueiros em cidades litorâneas ou banhadas por rios, no caso específico do Rio de Janeiro, entre o final do século XIX e início do XX. Antecedentes das principais equipes de futebol da cidade (Clube de Regatas Vasco da Gama, Clube de Regatas do Flamengo e Botafogo de Futebol e Regatas), os encontros de regatas se tornaram espaços de socialização importantes para parte da população.

O convívio nas regatas, além de ser espaço de formação de redes sociais e políticas, integra o personagem a personagens de outras esferas sociais, como "mocinhas francesas, jovens polacas e por batalhões de mulatas". Se o tempo é incerto, o espaço é determinado, o porto: recinto efervescente neste período, frequentado por imigrantes, marinheiros e funcionários, comerciantes, o local era fonte de subsistência e até mesmo de lazer e ascensão social.

A relação com o estrato marginalizado da população é contundente a partir daí. Pela configuração social da época e pelas gírias, polaca e francesa eram as alcunhas dadas às prostitutas (GRUMAN, 2006), enquanto isso, as mulatas, em sua maioria, pertenciam às classes baixas.

Faz-se então um possível paralelo. Pode-se encontrar nesse relato evidências da política de branqueamento promovida pela esfera federal. Para tal, incentivou-se a imigração de população europeia. Mesmo sendo concernente à prostituição de luxo, nesse caso, a imigração não deixa de atuar nesta mesma frente, a civilidade dos costumes, iniciando os jovens burgueses nas "artes do amor" (GRUMAN, 2006, p. 84). Porém, o mesmo trecho deixa claro, ao menos quanto à política de branqueamento, que esse nefasto programa não atinge sucesso pleno, já que, ao lado de polacas e francesas, há "batalhões de mulatas". Sugere ainda o forte apelo que a Revolta possui para a população negra.

A negação, ou sua tentativa, da negritude no Brasil pode ser entendida através de uma historicidade baseada em continuidades, através de um processo contínuo e programático de exclusão. Também contínua, cara à memória brasileira, é a violência por parte do Estado ao tratar reivindicações sociais. São acúmulos, vestígios sem inventários, como diria Gramsci, que ainda se fazem presentes.

Assim, apresentado o meio social no qual a história irá se desenvolver, João Bosco e Aldir Blanc voltam-se mais para a ação política e João Cândido. O saldo é violência por parte dos que repreendem o movimento. Das "rubras cascatas [que] jorravam das costas dos santos entre cantos e chibatas" surgem os primeiros indícios do que incitará o movimento rebelde.

Através das fontes históricas, sabe-se que a violência era empregada a um grupo especial da Marinha, os subalternos, que recebiam castigos físicos e em sua maioria eram negros. 
A utilização de "cantos" alude a um elemento cultural presente em diversas sociedades africanas. A música era elemento chave em diversas situações do cotidiano. Sugere-se compreender o canto como arma de afirmação mesmo durante os castigos físicos. Enquanto um apanhava, os outros mantinham e reafirmavam suas características culturais, cantando e, além disso, comoviam o "pessoal do porão", incitando-os a uma resposta.

$\mathrm{Na}$ historicidade proposta pela letra, pautada por continuidade e manutenção, a ação dos personagens - o Dragão do Mar e João Cândido - não precisa ser vista de forma apartada, pois é possível correlacioná-los na luta contra um sistema de opressão e violência caracterizado por uma política de Estado excludente e violenta que ainda perdura.

Eclode a Revolta com os gritos de João Gândido acompanhado por todo o "pessoal do porão". O brado vem exaltar e glorificar elementos significativos: piratas, mulatas, sereias, farofa, cachaça, baleias e lutas inglórias. Desconsideram-se por um momento "as lutas inglórias". Restam os estratos sociais marginalizados (piratas e mulatas), alimentos simbolicamente de uma classe social mais baixa (farofa e cachaça) e seres, fantasiosos ou reais, pertencentes ao mar (sereias, baleias e novamente piratas).

Parece a síntese daquilo que é a Revolta, daquilo que seus membros viviam cotidianamente. Indivíduos marginalizados e violentados, que viviam e praticavam seu ofício no mar. Ao estimar tais elementos e costumes indiretamente valorizavam-se todos que conviviam e faziam usufruto deles.

O "grito e os cantos" são também simbólicos. Além de um chamado, é a concretização metafórica da multivocalidade. Só através do cantar e do gritar que esses personagens conseguem direito à voz, à sua versão da história, já que, em grande medida, são apagados da memória e da história nacional.

E são esses apagamentos muitas vezes intencionais que tornam suas "lutas inglórias". Esquecidos, sem memória da oficialidade, só "através da nossa história" há de se ter mecanismos para jamais se esquecer daqueles que permanecem e reaparecem em meio às disputas que até hoje se arrastam, mesmo que o único "monumento" mnemônico sejam as "pedras pisadas do cais". Memórias apagadas, suplantadas, esses espaços precisam retomar sua valorização histórica, através de uma compreensão dos processos que lá ocorreram e dele ainda fazem parte. É um grito, uma ação, para que esse passado, deliberadamente escolhido, faça parte da nossa memória e história.

São as vistas de muitos, inglórios, como o era em sua época "o Dragão do Mar", pressionado pelos escravocratas; também João Cândido, que sofreu represálias por suas atitudes que iam de encontro aos interesses do alto oficialato da Marinha enquanto os compositores da música viviam sob o jugo da 
ditadura. É a repetição desmedida de um tipo de controle e discurso violento através de diferentes facetas.

Por fim, o desfecho da canção vem ironicamente amenizar todo o exposto. Retomando a ideia do primeiro verso, o último, como em um jogral, funciona como resposta: "mas faz muito tempo". Isso parece propor a mansidão, a aceitação, já que o narrado nada mais é do que um passado longínquo. O verso final atua como uma saída irônica dentro daquela perspectiva de uma historicidade de longa duração, com continuidades mais evidentes que rupturas, o que ajuda a compreender os mecanismos atuais de forma mais orgânica e contínua.

\section{vi. Conclusão}

Se a canção $O$ mestre-sala dos mares é um elogio claro à Revolta da Chibata também é uma crítica à ditadura. Esse paralelo histórico quase inevitável foi feito por boa parte dos autores vistos. Mas ao retomá-la enquanto uma canção documento, também é possível propor outras formas de interpretação, ao se escarafunchar através de suas camadas de significação.

Memória e história no tempo e no espaço permitiram a delimitação deste e uma incerteza daquele, o que ampliou as possibilidades para as análises históricas baseadas nessa canção.

Ao não se pautar por uma história linear e cronológica, a letra abre espaço para outras formas de compreensão do regime temporal, da longa duração. Historicidades não marcadas pelas rupturas, mas, sim, pelas permanências e continuidades, permitindo observar filogenias comuns, que: "pura e simplesmente [...] apenas os conteúdos históricos podem permitir descobrir a clivagem dos enfrentamentos e das lutas que as ordenações funcionais ou as organizações sistemáticas tiveram como objetivo, justamente, mascarar" (FOUGAULT, I999, p. II).

Os elementos constituidores da canção, como as memórias e o cotidiano, estão impregnados de história, e a pretensão é recuperá-la, não em sua totalidade, mas em sua possível pluralidade e multivocalidade.

\section{Referências bibliográficas}

ANDRADE, Edwilson da Silva. Um herói, uma história, uma canção. O discurso poético e os processos de significação em $O$ mestre-sala dos mares, de João Bosco e Aldir Blanc. Cadernos da FaEL. Nova Iguaçu/RJ, vol. 2, no 5, maio/ago., 2009. 
ALMEIDA, Silvia Capanema P. de. Do marinheiro João Cândido ao almirante Negro: conflitos memoriais na construção do herói de uma revolta centenária. Revista Brasileira de História. São Paulo, vol. 3I, nº 6I, 20II, p. 6I-84.

BAHIANA, Ana Maria. Profissão: artista. Categoria: autônomo e Independência ou Morte. In: Idem. Nada será como antes: a MPB nos anos $70-30$ anos depois. Edição revista. Rio de Janeiro: Editora Senac Rio, 2006, p. 312-323.

BATISTA, Cícero César Sotero. O lugar dos galos de briga: Aldir Blanc e a década de I970. Tese apresentada ao Programa de Pós-Graduação em Giência da Literatura da UFRJ, Instituto de Letras, Rio de Janeiro/RJ, 2010.

FIUZA, Alexandre Felipe. Entre cantos e chibatas: a pobreza em rima rica nas canções de João Bosco e Aldir Blanc. Campinas/SP: Dissertação apresentada ao Programa de Pós-Graduação em Educação da UNIGAMP/Faculdade de Educação, 200 I.

FOUCAULT, Michel. Em defesa da sociedade: curso no Collège de France (I975-I976). Tradução de Maria Ermantina Galvão. São Paulo/SP: Martins Fontes, I999.

GRAMSCI, A. The prison notebooks: Selections. Edição e tradução de Quintin Hoare e Geoffrey Nowell Smith. Nova York: International Publishers Co., I97I.

GRUMAN, Marcelo. A prostituição judaica no início do século XX: desafio à construção de uma identidade étnica positiva no Brasil. Revista de Antropologia Social. Curitiba/PR, Campos, vol. 7, no I, 2006.

LE GOFF, Jacques. História e memória. $4^{\mathrm{a}}$ ed. Campinas/SP: UNICAMP, I996.

MAESTRI, Mário. A Revolta da Chibata faz cem anos. Antíteses. Londrina/PR, vol. 3, 20IO, p. I-I5.

MARX, Karl. Manuscritos econômico-filosóficos e outros textos escolhidos. São Paulo: Abril Cultural, I978.

MARÇAL, Maria Antônia. O mestre-sala dos mares: a Revolta da Chibata e a consciência histórica dos alunos. Revista África e Africanidades, ano 2, nº 5, maio, 2009.

MENESES, Ulpiano Bezerra de. O objeto material como documento. Reprodução da aula ministrada no curso "Patrimônio cultural: políticas e perspectivas", organizado pelo IAB/Condephaat, I980.

MOREL, Edmar, A Revolta da Chibata. $4^{\underline{a}}$ ed. Rio de Janeiro: Edições Graal/Paz e Terra, I986 (I- ed., I958).

NAPOLITANO, Marcos. MPB: a trilha sonora da abertura política (I975/I982). Revista de Estudos Avançados. São Paulo, vol. 24, n 69, 2010.

OLIVEIRA, Marcelo A. G. \& SIQUEIRA, Gustavo S. A Revolta da Chibata entre cascatas, estátuas e navios. Insight Inteligência, edição 6I: Todo cuidado é pouco, ano XVI, $2^{\circ}$ trimestre, jul. 2013 . 
PROJETO MEMÓRIA. João Cândido. A luta por direitos humanos. Fundação Banco do Brasil, Petrobrás e Acan, 2008.

SOUSA, Gláudio Barbosa de. Marinheiros em luta: a Revolta da Chibata e suas representações. Dissertação apresentada ao Programa de Pós-Graduação em Giências Sociais da Universidade Federal de Uberlândia, Uberlândia/MG, 2012.

TATIT, Luiz. Canção, estúdio e tensividade. Revista da USP. São Paulo, no ${ }^{4}$, dez./ jan./fev., I989-90.

VENTURA, Zuenir. O vazio cultural \& a falta de ar (parte). In: GASPARI, Elio e HOLANDA, Heloisa Buarque de. Cultura em trânsito: da repressão à abertura. Rio de Janeiro: Aeroplano Editora, 2000, p. 40-65.

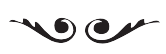

Thiago Kater - Graduado em História pela Universidade de São Paulo em 2012. Graduando de Letras pela Universidade de São Paulo.

thiagokater@gmail.com 